\title{
Optimum Selection of Renewable Energy Powered Desalination Systems ${ }^{+}$
}

\author{
Ahmad H. Al-Jabr * and Rached Ben-Mansour \\ Department of Mechanical Engineering, King Fahd University of Petroleum \& Minerals (KFUPM), \\ Dhahran 31261, Saudi Arabia; rmansour@kfupm.edu.sa \\ * Correspondence: aljabrah@kfupm.edu.sa; Tel.: +966-56-919-4465 \\ + Presented at the 3rd EWaS International Conference on "Insights on the Water-Energy-Food Nexus", \\ Lefkada Island, Greece, 27-30 June 2018.
}

Published: 31 August 2018

\begin{abstract}
Research and development of desalination technologies are becoming highly important because of the rapid increase in freshwater demand. Researchers are continually working on improving the existing desalination technologies and exploring new methods and ideas to desalinate salty water in order to come up with cost-effective systems. Comparisons between different renewable powered desalination technologies were mainly based on different system capacity, energy source system, feed-water salinity and system components. This makes the economical comparison almost impossible. There is an existing gap in having an economical comparison to different renewable energy powered desalination systems with the same basics such as availability of renewable and water resources. This research is an attempt to provide a systematic methodology to obtain the most cost-effective renewable energy powered desalination system.
\end{abstract}

Keywords: desalination; renewable energy; reverse osmosis; wind; photovoltaic

\section{Introduction}

Water is a critically important element in mankind's life. However, Water demand is rapidly increasing because of the population increase and uncontrolled human and industrial usage. Eight and a half billion gallons/day of water is desalinated over the world [1]. This number is expected to increase in the near future because of the continuous increase in population and industry. Desalination is recognized as an energy-intensive process where $50 \%$ of the total cost of desalination is energy cost.

Increasing conventional fossil fuels costs, conventional resources being depleted, its environmental effects lead people to think in other power alternatives. On the other side, renewable energy is abundant on earth, available, sustainable, free and environmentally friendly.

Proper matching between Renewable energy and desalination system should be carefully investigated to end up with a rigid system that provides water at reasonable cost. Figure 1 shows the most promising combinations of Renewable Energy Desalination Systems (REDS) as recommended by [1]. Solar and wind energy coupled with desalination systems have been implemented and seems to be promising more than other renewable-desalination combinations [2]. The most renewabledesalination combinations used are PV-RO [3,4] and solar thermal-MED [4].

Karagiannis \& Soldatos [5] provided water desalination cost review and concluded that the cost of water is location dependent. Al-Karaghouli \& Kazmerski [6] stated that desalination technologies powered by renewable energy are proven technology and economically competitive in remote regions. A comparison of four different renewable-desalination combinations has been carried by [7] for a plant capacity of $500 \mathrm{~m}^{3}$. The results show that RO-Wind and MVC-Wind have almost the same 
specific cost of 1.61 and $1.62 \$ / \mathrm{m}^{3}$, respectively. RO-PV is costing $2.99 \$ / \mathrm{m}^{3}$ while MVC-PV with the height cost of $3.97 \$ / \mathrm{m}^{3}$. Koroneos et al. [7] work was done for an only plant capacity of $500 \mathrm{~m}^{3}$ and they did not study other promising renewable desalination combinations. Bourouni et al. [8] presented design models of five different configurations for two combinations which are PV-RO and Wind-RO. The authors did not include full economical study and comparison between the configuration.

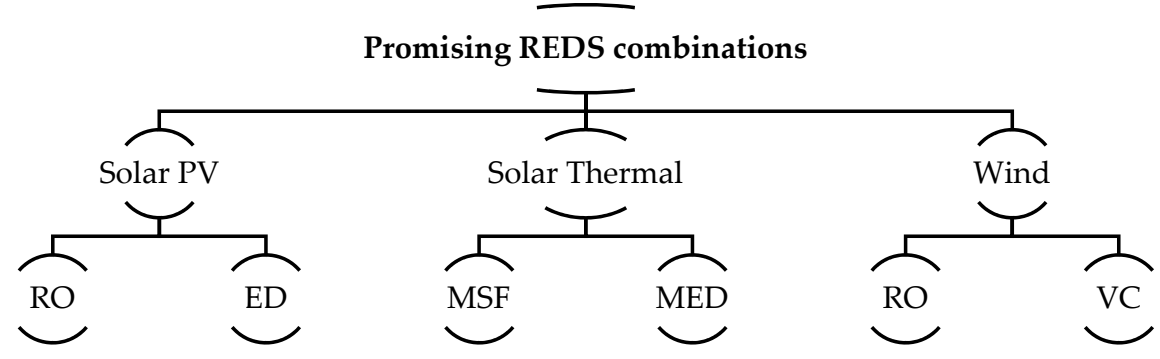

Figure 1. Most Promising REDS combinations.

The selection of the appropriate method should go through a careful study of location conditions and local circumstances [1]. Gude et al. [2] mentioned several parameters that affect the decision of the selection. These parameters include plant capacity, feed-water salinity, availability of grid, technical support and infrastructure, remoteness and local renewable resources. It is observed that most of the existing comparisons between different desalination technologies and specifically renewable powered desalination technologies were mainly based on different system capacity, energy source system, feed-water salinity and system components. This makes the economical comparison almost impossible. There is an existing gap in having an economical comparison of different renewable powered desalination systems under the same conditions such as availability of renewable energy and water resources. This research is an attempt to fulfill this gap by providing a systematic methodology to obtain the most cost-effective renewable energy powered desalination system given the capacity required, water salinity and the resources of a given location.

\section{Selection Methodology}

To develop an optimum selection of renewable energy powered desalination system given the renewable energy and water resources of site geographical location the following methodology is followed:

- Based on water capacity needed and feed-water salinity, the energy needed to desalinate the required capacity of water using different desalination systems such as reverse osmosis, multieffect desalination is evaluated based on updated published models.

- Cost models are used to estimate installation, operation \& maintenance and total costs based on the local costs for the geographical location considered.

- Using renewable energy data of the location considered, renewable power generation-systems sizes that are used to power the desalination systems are determined. Renewable energy generation systems include solar-thermal, solar PV and wind turbine.

- Cost models are also used to estimate installation, operation \& maintenance and total costs.

- Specific cost per cubic meter of distillate water is obtained for each renewable-desalination combination using the cost of both systems.

- Specific costs for all combinations are compared and the combination that has the lowest specific cost is selected as the optimum renewable powered desalination system.

The above methodology is represented by a flowchart shown in Figure 2.

The first step in implementing the methodology is to look at several renewable energy powered desalination systems. In order to limit our search space, we will only consider the most promising and practical combinations of renewable energy subsystem and desalination subsystem as discussed 
in the introduction. Based on the above literature, the most promising combinations are RO-Wind, RO-PV, and Solar thermal-MED.

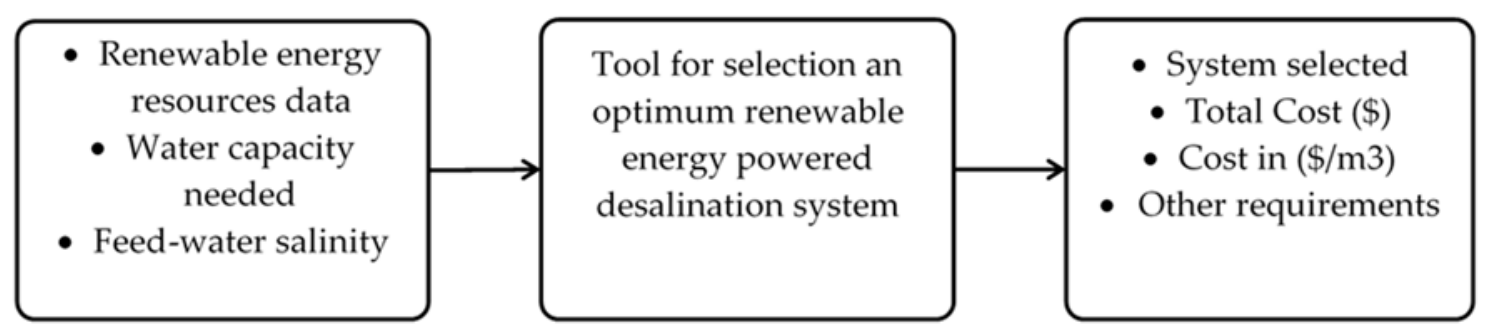

Figure 2. Methodology flowchart.

\section{RO-Wind}

In order to come up with the appropriate design of Wind-RO, the following methodology is applied. The presented methodology uses water storage to ensure water availability instead of energy storage. This selection makes the system more reliable, more economical, feasible especially for large capacity, more environmentally friendly and it is in line with our primary goal of water production. The methodology is as the following:

- $\quad$ Based on water capacity needed $\left(\mathrm{Mn}_{n, a v g}\right)$ and feed-water salinity, the size needed to desalinate the required capacity of water using reverse osmosis desalination system is evaluated. The size of the RO system is mainly determined by the number of pressure vessels (NPressurevessels).

- $\quad$ Once the size of the RO system is decided, the power required is evaluated then the number of wind turbines ( $\mathrm{N}_{\text {Turbines }}$ ) is determined using yearly average wind speed.

- $\quad$ Power produced by a wind farm in each month is evaluated $\left(P_{\text {wind,i, }} \mathrm{i}=1,12\right)$ based on actual weather data.

- Monthly and Monthly average water production is evaluated ( $\mathrm{Md}_{\mathrm{d}, \mathrm{i}} \mathrm{i}=1,12$ \& $\mathrm{M}_{\mathrm{d}, \text { avg }}$ ) based on monthly power production.

- In some months, all energy produced is utilized to desalinate water. In others, the energy produced is more than the maximum power required by the desalination system so some of the energy is excess. Excess of Energy (EE) is evaluated.

- If average water production is less than average water demand and there is no excess of energy this means the power system is not enough to produce the required water capacity so we need to size up the power system by one additional turbine. If there is energy excess we increase the size of the RO system by adding one pressure vessel.

- $\quad$ Finally, the storage tank status is evaluated at the end of each month (Tank $\mathrm{i}, \mathrm{i}=1,12)$ to ensure availability of water. Size of the storage tank is determined by the maximum water volume available in the storage tank at the end of each month and the minimum storage size is determined by water demand for 30 days.

- $\quad$ Total and specific cost of power, desalination, and storage systems are evaluated.

The above-explained methodology for RO-Wind is depicted in Figure 3.

It is important to recall that we use water storage instead of energy storage. For this purpose, the status of the tank is monitored for the first twelve months to guarantee water supply by the system in all months. Size of the tank is determined by the maximum water storage volume required and the minimum storage tank size is determined by water demand for one month. Water production is not the same in all months. It is a function of renewable resources available and renewable power system size. So, water production in some months will be more than the needed to balance the months with lower renewable resources. Therefore, the status of the water storage tank is strongly dependent on the starting month.

The wind turbine model is obtained from its characteristics curve. Several polynomials are used to increase the accuracy of programming. The mathematical thermodynamics model of RO system is 
developed as presented in [9]. Cost evaluation for the reverse osmosis system is obtained by the model presented in [10].

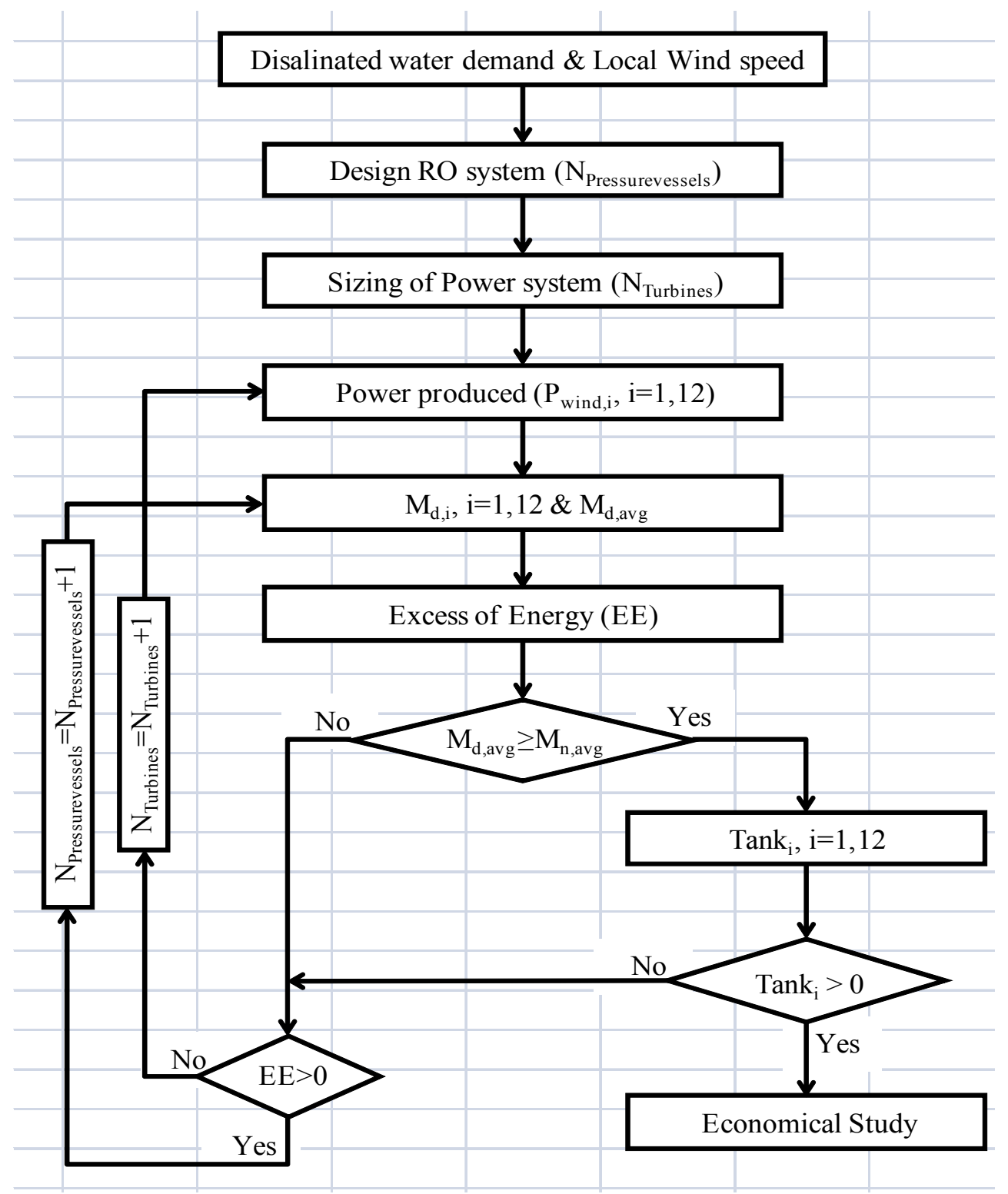

Figure 3. Flowchart of the presented methodology for RO-Wind.

\section{RO-PV}

The methodology followed in RO-PV is very similar to RO-Wind except in having full-day operation evaluation for an average day in each month.

The modeling of a PV array included the solar radiation modeling and PV power generation modeling. The solar radiation modeling estimates the radiation incident on a tilted surface. The model is obtained from [11]. The PV generation model estimates the PV array output power based on the incident solar radiation, weather conditions, and PV panel specification. The equations used are obtained from [12]. In the present analysis, the incident solar radiation is evaluated for each hour on an average day in each month. An average day of each month and their number of the day in the year, $\mathrm{n}$ is obtained from [11]. The presented PV power generation model was implemented in Engineering Equation Solver (EES) software package. The developed model is validated against the results presented in [12]. 


\section{Solar Thermal-MED}

Parabolic troughs where selected over the other CSP technologies because of its higher performance and ability to provide high temperatures. Parabolic trough collectors (PTC) can be operated with one or two axis solar tracking to maximize solar energy absorption. Two-axes is exactly following the sun at zero angle. However, it is more difficult to operate and it is not cost-effective. One-axis configuration could be horizontal, vertical or polar. According to [13], the polar configuration is recommended.

The mathematical thermodynamics model of Parabolic trough system presented by the National Renewable Energy Laboratory (NREL) in [14] is used and utilized. The parabolic trough collector used in this analysis is LS-2. The geometrical characteristics of LS-2 are in Table 1. Costs are obtained using the correlations given by [15].

Table 1. Geometric parameters of the solar collector LS-2 [14].

\begin{tabular}{cc}
\hline Parameter & Value (m) \\
\hline inside diameter of absorber pipe & 0.066 \\
outside diameter of absorber pipe & 0.070 \\
inside diameter of glass envelope & 0.109 \\
Outside diameter of glass envelope & 0.115 \\
Aperture's width & 4.8235 \\
\hline
\end{tabular}

For MED analysis, several configurations are presented in literature including forward feed, backward, parallel and parallel/cross. The main difference is the direction of the feed and brine flows. Sharaf et al. [15] concluded that parallel configuration is the most applicable out of four studied configurations because of its higher gain ratio, specific water cost, and areas. In addition, El-Dessouky et al. [16] compared parallel and parallel/cross and they concluded that parallel/cross is more effective than the parallel configuration. The main difference between the two configurations is that in parallel/cross the brine of one effect is sent to the next effect where flashing is taking place in addition to the vaporization. The detailed mathematical thermodynamics model of MED parallel/cross system is developed as presented in $[9,16]$. Economical evaluation of the multi-effect distillation parts is estimated based on correlations provided in [15,17].

Two supplementary components are also required. These are the burner and the boiler heat exchanger. The objective of the burner is to increase the temperature of the heat transfer fluid if the energy supplied by the solar system is lower than the design temperature. The objective of the boiler is transferring the heat collected by the heat transfer fluid from the solar collector and the burner to the water circuit to derive the MED desalination system.

The design methodology for MED-Solar thermal is as follows:

1. MED desalination plant is designed based on the water demand capacity.

2. Thermal power required to operate the MED plant is evaluated.

3. The solar field is designed based on the required thermal power and design solar irradiation (IDesign). The implemented IDesign in this study is the yearly maximum solar irradiation

4. Using hourly solar irradiation (I), heat transfer fluid's (HTF) outlet temperature is evaluated.

5. Auxiliary heat is required if I is less than IDesign to maintain the HTF temperature at the design temperature. Auxiliary burner is used with natural gas.

6. Performance parameters and cost estimation of the MED-Solar thermal system are calculated.

The presented methodology is shown in Figure 4. The parameters at which the analysis is performed are shown in Table 2. 


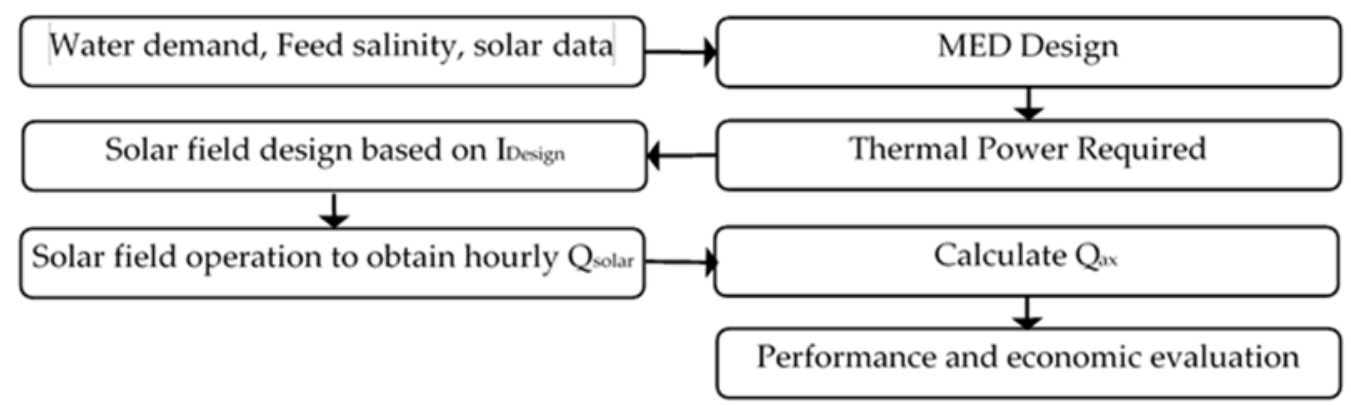

Figure 4. Design Methodology of MED-Solar thermal.

Table 2. Design parameter of MED-Solar thermal.

\begin{tabular}{cc}
\hline Parameter & Value \\
\hline Mdistillate $_{\text {c }}$ & $1000 \mathrm{~m}^{3}$ \\
$\mathrm{~T}_{\mathrm{cw}}$ & $25 \mathrm{C}$ \\
$\mathrm{T}_{\mathrm{f}}$ & $35 \mathrm{C}$ \\
$\mathrm{T}_{\mathrm{s}}$ & $75 \mathrm{C}$ \\
$\mathrm{X}_{\mathrm{f}}$ & $42,000 \mathrm{PPM}$ \\
$\mathrm{X}_{\mathrm{B}}$ & $70,000 \mathrm{PPM}$ \\
No. of effects & 8 \\
Collector type & LS-2 \\
Heat Transfer Fluid & Therminol VP1 \\
Fuel & Natural gas \\
\hline
\end{tabular}

\section{Results \& Discussion}

To illustrate the application of the methodology, different cases are analyzed and compared for the city of Dhahran, Saudi Arabia. For RO systems, the fixed parameters for which these cases are analyzed are summarized in Tables 3 and 4 show the results obtained for RO-Wind and RO-PV systems. Figures 5 and 6 show the average water production of each month for RO-Wind and RO-PV systems, respectively.

Results show that the cost of water by wind is less than the cost of water by solar. For daily average water demand of $1000 \mathrm{~m}^{3}$, cost of water in RO-Wind is $1.366 \$ / \mathrm{m}^{3}$ while in RO-PV it is 2.119 $\$ / \mathrm{m}^{3}$. Table 4 shows that the number of pressure vessels in RO-PV is almost three times the number of vessels needed in RO-Wind for the same water capacity. In addition, the amount of power installed in RO-PV system is $80 \%$ more than the amount of power installed in RO-Wind. These two factors impose RO-PV cost to be more than RO-Wind cost by $55 \%$. This shows that the main reasons behind this difference are the larger amount of installed power and the larger desalination system (or storage systems in case of energy storage) caused by the long-time off-operation during the night.

A similar analysis to RO-Wind and RO-PV is done for MED-solar thermal. The basic design parameter and results are illustrated in Table 5. Cost of such a system is breaking down mainly into the cost of MED system and solar system in addition to fuel cost and supplementary systems. Solar energy collected by the solar field for typical days in four months are presented in Figure 7. We can see from the figure that the system is not operated solely by solar unlike RO-PV and RO-Wind systems in which operated $100 \%$ by renewable energy. Solar share for this case is around $24.4 \%$. To increase solar share, we could decrease IDesign to obtain larger solar collector system and, as a result, capturing more solar energy. However, on the other side, if solar irradiation is more than IDesign, some of the solar energy will not be captured due to the limitation in the MED system. For daily average water demand of $1000 \mathrm{~m}^{3}$, cost of water in MED-Solar is $2.282 \$ / \mathrm{m}^{3}$. 
Table 3 Fixed Design Parameters of RO-Wind and RO-PV cases.

\begin{tabular}{cc}
\hline Quantity (Unit) & Value \\
\hline Daily water demand $\left(\mathrm{m}^{3}\right)$ & 1000 \\
Feed water salt concentration $(\mathrm{PPM})$ & 45,000 \\
Feed water Temperature $\left({ }^{\circ} \mathrm{C}\right)$ & 25 \\
Recovery Ratio $(\%)$ & 30 \\
Membrane Area $\left(\mathrm{m}^{2}\right)$ & 35.4 \\
Number of elements in each pressure vessel & 7 \\
\hline
\end{tabular}

Table 4. Results of RO-Wind and RO-PV systems.

\begin{tabular}{ccc}
\hline Quantity & RO-Wind & RO-PV \\
\hline Daily Water Demand $\left(\mathrm{m}^{3}\right)$ & 1000 \\
Daily Average Water Production $\left(\mathrm{m}^{3}\right)$ & 1027 & 1016 \\
\# of turbines/panels & 6 & 8778 \\
\# of Pressure Vessels & 10 & 27 \\
\# of Storage Tanks & 3 & 3 \\
Specific Cost of Power System $\left(\$ / \mathrm{m}^{3}\right)$ & 0.2675 & 0.6892 \\
Specific Cost of Desalination System $\left(\$ / \mathrm{m}^{3}\right)$ & 0.9406 & 1.270 \\
Specific Cost of Storage System $\left(\$ / \mathrm{m}^{3}\right)$ & 0.1582 & 0.1599 \\
Water Specific Cost $\left(\$ / \mathrm{m}^{3}\right)$ (based on water production) & 1.366 & 2.119 \\
\hline
\end{tabular}

Table 5. Design Parameter and Results of MED-Solar combination.

\begin{tabular}{ccc}
\hline Parameter & Value & Unit \\
\hline Mdemand & 1000 & $\mathrm{M}^{3} /$ day \\
$\varphi$ & 26.1 & degrees \\
$X_{\text {feed }}$ & 45000 & $\mathrm{PPM}$ \\
IDesign & $\mathrm{I}_{\max }=991.8$ & $\mathrm{~W} / \mathrm{m}^{2}$ \\
Specific cost of MED sub-system & 0.9982 & $\$ / \mathrm{m}^{3}$ \\
Specific cost of solar sub-system & 0.5529 & $\$ / \mathrm{m}^{3}$ \\
Specific cost of MED-solar thermal & 2.282 & $\$ / \mathrm{m}^{3}$ \\
Solar collector length & 61.54 & $\mathrm{M}$ \\
Solar collector rows & 23 & $\#$ \\
\hline
\end{tabular}

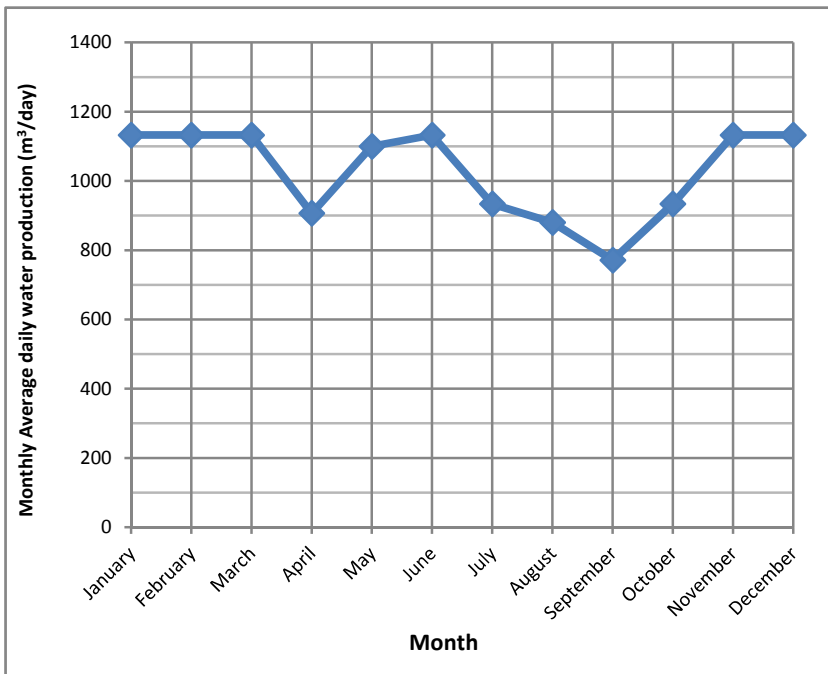

Figure 5. Monthly Average Daily Water Production of RO-Wind. 


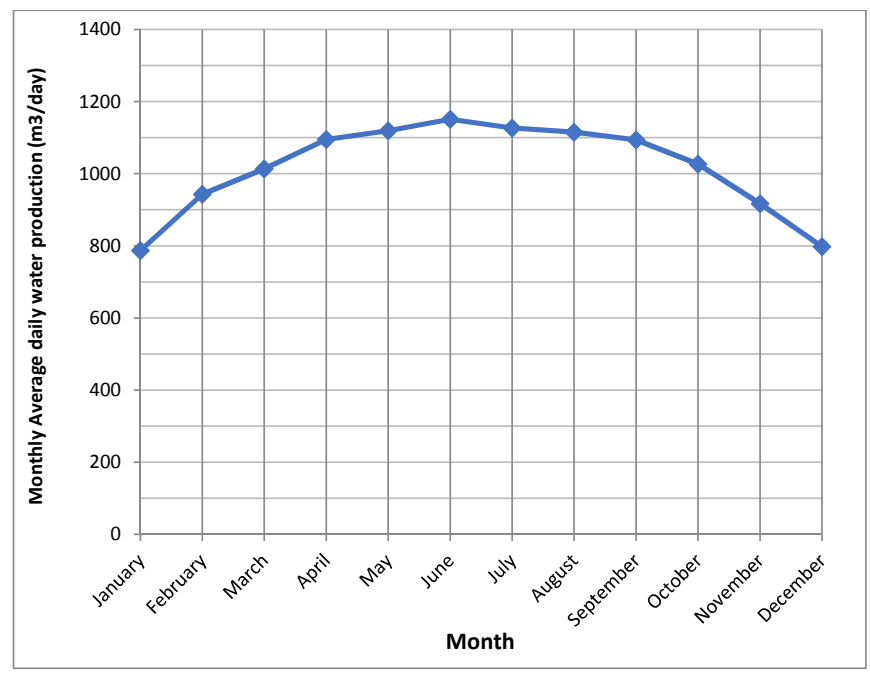

Figure 6. Monthly Average Daily Water Production of RO-PV.

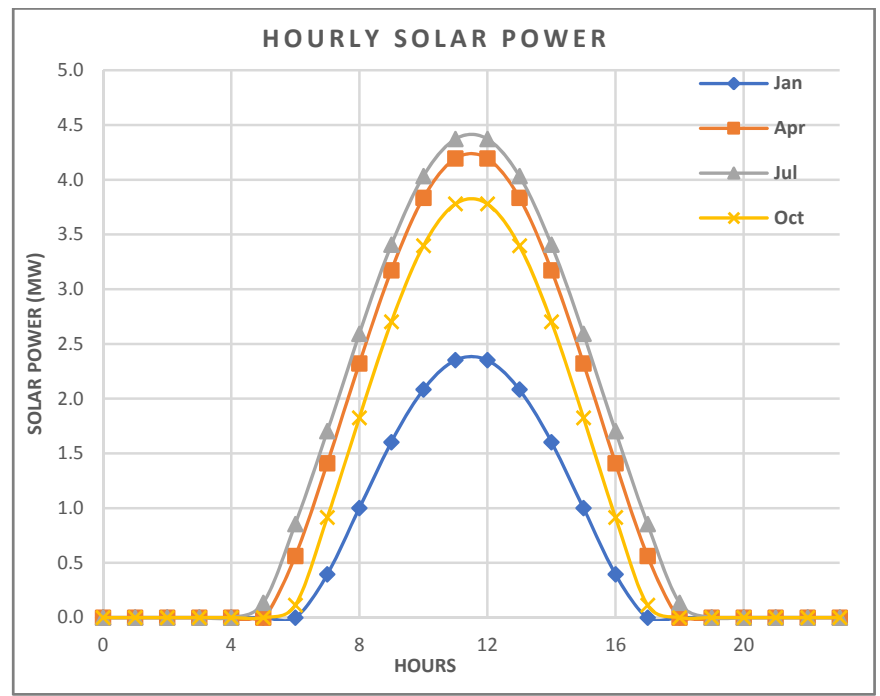

Figure 7. Solar filed collected energy over the day in typical four months for Idesign $=I_{\max }$ (Water demand $=1000 \mathrm{~m}^{3} /$ day, Feed Concentration $\left.=45,000 \mathrm{PPM}\right)$.

\section{Conclusions}

We have presented a thermo-economic methodology for selecting the most cost-effective renewable energy powered desalination system given a geographical location, based on the weather data and required freshwater demand. The methodology has been formulated based on the common published models of renewable energy and desalination subsystems. In order to facilitate the use of this methodology, we have implemented it in EES software (A version of this software can be obtained from http://www.fchart.com/ees/) and used the code to simulate several practical cases.

For the case of Dhahran, Saudi Arabia, the method predicted that an RO-Wind system produced desalinated water at a cost of $\$ 1.366 / \mathrm{m}^{3}$ for a daily demand of $1000 \mathrm{~m}^{3}$. This was in favor of an RO$\mathrm{PV}$ and MED-Solar systems with costs of $\$ 2.119 / \mathrm{m}^{3}$ and $\$ 2.282 / \mathrm{m}^{3}$, respectively.

Acknowledgments: The authors of this article sincerely acknowledge the support of King Fahd University of Petroleum \& Minerals (KFUPM). The support of the Mechanical Engineering Department and the Deanship of Research at KFUPM are acknowledged for their support during the course of this work. 


\section{References}

1. Al-Karaghouli, A.; Renne, D.; Kazmerski, L.L. Solar and wind opportunities for water desalination in the Arab regions. Renew. Sustain. Energy Rev. 2009, 13, 2397-2407, doi:10.1016/j.rser.2008.05.007.

2. Gude, V.G.; Nirmalakhandan, N.; Deng, S. Renewable and sustainable approaches for desalination Renew. Sustain. Energy Rev. 2010, 14, 2641-2654, doi:10.1016/j.rser.2010.06.008.

3. Ghaffour, N.; Bundschuh, J.; Mahmoudi, H.; Goosen, M.F. Renewable energy-driven desalination technologies: A comprehensive review on challenges and potential applications of integrated systems Desalination 2015, 356, 94-114, doi:10.1016/j.desal.2014.10.024.

4. Kalogirou, S.A. Seawater desalination using renewable energy sources. Prog. Energy Combust. Sci. 2015, 31, 242-281, doi:10.1016/j.pecs.2005.03.001.

5. Karagiannis, I.C.; Soldatos, P.G. Water desalination cost literature: Review and assessment. Desalination 2008, 223, 448-456, doi:10.1016/j.desal.2007.02.071.

6. Al-Karaghouli, A.; Kazmerski, L.L. Energy consumption and water production cost of conventional and renewable-energy-powered desalination processes. Renew. Sustain. Energy Rev. 2013, 24, 343-356, doi:10.1016/j.rser.2012.12.064.

7. Koroneos, C.; Dompros, A.; Roumbas, G. Renewable energy driven desalination systems modelling. J. Clean. Prod. 2007, 15, 449-464, doi:10.1016/j.jclepro.2005.07.017.

8. Bourouni, K.; Ben M'Barek, T.; Al Taee, A. Design and optimization of desalination reverse osmosis plants driven by renewable energies using genetic algorithms. Renew. Energy 2011, 36, 936-950, doi:10.1016/j.renene.2010.08.039.

9. El-Dessouky, H.T.; Ettouney, H.M. Fundamentals of Salt Water Desalination; Elsevier: New York, NY, USA, 2002.

10. Nafey, A.; Sharaf, M. Combined solar organic Rankine cycle with reverse osmosis desalination process: Energy, exergy, and cost evaluations. Renew. Energy 2010, 35, 2571-2580, doi:10.1016/j.renene.2010.03.034.

11. Duffie, J.; Beckman, W. Solar Engineering of Thermal Processes; John Wiley and Sons: Hoboken, NJ, USA, 2006.

12. Ahmad, N.; Sheikh, A.K.; Gandhidasan, P.; Elshafie, M. Modeling, simulation and performance evaluation of a community scale PVRO water desalination system operated by fixed and tracking PV panels: A case study for Dhahran city, Saudi Arabia. Renew. Energy 2015, 75, 433-447, doi:10.1016/j.renene.2014.10.023.

13. Gholinejad, M.; Bakhtiari, A.; Bidi, M. Effects of tracking modes on the performance of a solar MED plant. Desalination 2016, 380, 29-42, doi:10.1016/j.desal.2015.11.015.

14. Forristall, R. Heat Transfer Analysis and Modeling of a Parabolic trough Solar Receiver Implemented in Engineering Equations Solver; National Renewable Energy Laboratory: Golden, CO, USA. 2003.

15. Sharaf, M.; Nafey, A.; García-Rodríguez, L. Exergy and thermo-economic analyses of a combined solar organic cycle with multi effect distillation (MED) desalination process. Desalination 2011, 272, 135-147, doi:10.1016/j.desal.2011.01.006.

16. El-Dessouky, H.T.; Ettouney, H.M.; Mandani, F. Performance of parallel feed multiple effect evaporation system for seawater desalination. Appl. Therm. Eng. 2000, 20, 1679-1706.

17. Nafey, A.; Fath, H.; Mabrouk, A. Thermoeconomic design of a multi-effect evaporation mechanical vapor compression (MEE-MVC) desalination process. Desalination 2008, 230, 1-15, doi:10.1016/j.desal.2007.08.021.

(C) 2018 by the authors. Licensee MDPI, Basel, Switzerland. This article is an open access article distributed under the terms and conditions of the Creative Commons Attribution (CC BY) license (http://creativecommons.org/licenses/by/4.0/). 